\title{
Common Diseases and Some Demographic Characteristics among Saudi Women
}

\author{
Ahmed Abdulrahman Al-Haramlah ${ }^{1}$, Fawziah Al-Bakr ${ }^{2} \&$ Haniah Merza $^{3}$ \\ ${ }^{1}$ Northern Border University, Saudi Arabia \\ ${ }^{2}$ King Saud University, Saudi Arabia \\ ${ }^{3}$ Princess Norah University, Riyadh, Saudi Arabia \\ Correspondence: Ahmed Abdulrahman Al-Haramlah, Northern Border University, Saudi Arabia. Tel: \\ 966-566-602-503. E-mail: ahmad_alharamlah@yahoo.com
}

Received: July 11, 2015 Accepted: August 25, 2015 Online Published: November 25, 2015

doi:10.5539/ies.v8n12p94 URL: http://dx.doi.org/10.5539/ies.v8n12p94

\begin{abstract}
This study aimed to detect the common diseases among Saudi women and their relationship with the level of physical activity and some variables. This study was applied to 1233 Saudi woman in different regions of the Kingdom, and adopted to explore the common diseases: obesity, hypertension, diabetes, cholesterol and asthma.

The study results showed the existence of a statistically significant relationship between the common diseases among Saudi women and the variables of educational level, the nature of the profession, the social status, the justification of the practice of physical activity, the rate of participation in physical activity per week, the practice of physical activity in relation to asthma and the number of children with regard to obesity.

The study provided a number of recommendations including: the need to strengthen the role of culture in promoting physical activity by women, through health education via the health centers in the Kingdom.
\end{abstract}

Keywords: common diseases, physical activity, aerobic exercise, sports clubs

\section{Background}

The practice of women's sports activities help women to refine their talents. The trend is to create good habits and to win social and moral qualities and prevention of common diseases infecting them. It also helps to show restraint and respect for self and others and the community, the sport of women's activities provide fitness to ensure that its integrated balanced life free of common diseases.

The practice of physical activity have an important role in the prevention and treatment of many diseases, such as: type II diabetes, heart disease and many types of cancer. The World Health Organization (WHO) showed that the lack of physical activity is considered most universally fourth factor dangers of individuals' life to cause the occurrence of deaths worldwide. It is responsible of the occurrence of $6 \%$ of deaths in the world and an estimated 3.2 million deaths per year, including 2.6 million in developing countries and 670,000 premature deaths (C3 Collaborating for Health, 2011).

The practice of physical activity considered the most important methods and strategies that contribute to the prevention and treatment of diseases caused by lack of exercise activities. Merza et al.'s (2013) studies noted the prevalence of common diseases among Saudi women was the most important of these diseases: asthma, obesity, hypertension, high cholesterol, hyperglycemia and it was directly related to the level of sports practice and the lack of women's sports facilities available in the Saudi society.

Studies have shown that heart disease is the leading killer of women in the United States, in addition to obesity, diabetes, high cholesterol, hypertension, especially American women of African origin. The studies have shown that there is a gap between the health practices and the behavior of American women of the middle class, where they are more likely to be overweight due to low physical activity (Reeder, 2011, p. 323).

The women's exercise of physical activity affects his physical on both sides: first one, that it affects the causes of her infection during childhood and adulthood, where studies have indicated the existence of a positive relationship between physical activity and a range of factors that influence women's physical health, including diabetes, hypertension and the ability to use fat for energy. The second side, that physical activity reduces the 
risk of chronic diseases in life at a later time (stage age), such as cancer, diabetes and coronary heart disease, have their origins in the childhood, and the practice of regular physical activity from childhood helps to improve bone health, and thus prevent osteoporosis, which mainly affects women (Bailey, Wellard, \& Dismore, 2004, p. 54).

The researchers see through this study that the spread of diseases among Saudi women due to lack of physical activity as indicate the results of Merza et al. (2013) studies, which revealed common diseases prevalent among Saudi women from their point of view in the main regions of Saudi Arabia. This leads to the search of the relationship of these common diseases among Saudi women with some variables.

Researchers looking through this study to learn about this relationship as a problem of this research and to answer to the following main question: what is the relationship between the common diseases among Saudi women with certain variables?

\section{Objectives and Importance}

This study aimed to identify the relationship between the common diseases of Saudi women and their relationship with certain variables, including: area of residence, age group, weight, nature of occupation, educational level, marital status, justification for the practice of physical activity and the rate of physical activity. Sports medicine is one of modern medical branches that specialize in the prevention and treatment of diseases caused by lack of exercise, and which met with great interest from stakeholders and researchers in the field of sport. Among the studies that have examined this issue we found that of Albecker et al. (2013), this study also aimed to provide advice and solutions that help researchers and Saudi women in particular to combat diseases who undergo them through the exercise of physical activities.

The importance of this study is to determine the relationship between the common diseases suffered by Saudi women and the level of their practicing of sports activity in all its types, and to stand on the best ways to reduce the spread of these diseases, and thus to develop solutions that would reduce these diseases. Due to the fact of the foundation that built upon to solve any problem is to know its size and dimensions and its relationship with some of other variables, this study investigated the relationship between the common diseases among Saudi women and sport and some other variables.

\section{Hypotheses}

To achieve the purpose of this study that represented of detection of the common diseases among Saudi women and their relationship with the level of practicing physical activity and some variables, we have developed the following hypotheses:

1) "There is no statistically significant relationship between common diseases among Saudi women and physiological variables (age group and weight)".

2) "There is no statistically significant relationship between common diseases among Saudi women and social variables (residence area, educational level, children's number, nature of the profession and social situation".

3) "There is no statistically significant relationship between the common diseases among Saudi women and some sportive variables (practicing of physical activity, justifications of practicing the physical activity and practicing physical activity rate per week".

\section{Previous Studies}

Scientists and researchers in the field of education and sport were interested in women's sports. A variety of research and studies in this area have been developed. Here are reviewed the most important of these studies.

The Aljaffery 'study in 2014 aimed to know the attitudes of the students of King Abdul Aziz University in Saudi Arabia about the sport. This study is applied to 275 male and female students, in addition to the disclosure of the impact of physical activity on health, social, psychological and scientific aspects. The results of the study showed that the trends were positive as well as the absence of differences in the attitudes of students according to body mass and magnitude of cumulative average index. While the results show the existence of differences in the trends in the field of health according to the sex variable in males' favor.

Merza et al. (2013) conducted a study aimed to detect Saudi women's attitudes towards practicing sports activities and strategies for early intervention to address the impact on human health due to the low level of these activities. This study developed a questionnaire to measure the Saudi women's attitudes towards sports activities, and applied to a sample of 1233 Saudi women. The most prominent results are:

The Saudi women's attitudes towards sports practices are positives, high and significant. The results of the study 
have been proven the existence of statistically significant differences among Saudi women due to the area of residence, where the tendencies of Saudi women living in the East are less important than those of Saudi women resident in the central and the Southern region. Also, there are statistically significant differences in Saudi Arabia women's attitudes towards sports activities attributed to the age group, where the Saudi women's trends are higher in women aged 33 years and under, compared to those of 34 and above. The weight is also a statistically significant factor; in fact there are differences between women who weigh between $63-68 \mathrm{~kg}, 75-79 \mathrm{~kg}$ and 80 $\mathrm{kg}$ or more, where the trends of Saudi women are higher in women who weigh $75-79 \mathrm{~kg}$. There are significant differences in the Saudi women attitudes toward sports activities attributed to the level of education, these differences are between women with a bachelor's degree and non-educated women, where the attitudes of Saudi women are higher among women with a bachelor's degree. In addition to existence of statistically significant differences in the Saudi women's attitudes towards sports activities attributed to the nature of the profession. These differences are between housewives, workers in other functions and teachers. The attitudes of the teachers are higher. Finally, the results indicated that there are no statistically significant differences in the attitudes of Saudi women about sports activities attributed to marital status.

Wojtyła et al. (2011) carried out a study aimed to detect the practice of physical activity among women of childbearing age and during pregnancy in Poland during the period from 2010 to 2011, where the practice of physical activity among girls affects their ability to child bear. Scientific reports indicate the low of physical activity level among adolescents, especially for girls. This study was applied to 3940 women including 730 under 15 years, in addition to 6252 pregnant women. The survey was conducted among school students during the last quarter of 2011, while the implementation of the survey among pregnant women is twice: the first one in the second quarter of 2010 and the second one in the third quarter of 2011. The study's results showed a decline in physical activity rate among young and pregnant women. As well as the study's results showed a trend towards decreased physical activity for women according to age.

A study conducted by Midhet, Al Mohaimeed, and Sharaf, (2010), aims to detect dietary practices, physical activity and health education in Al-Qassim region in Saudi Arabia. The study is applied on 2784 patient including 1804 male and 980 female who visit primary health care centers in Al-Qassim region and where the incidence of diabetes, hypertension, pressure and coronary artery disease increased, that threatens the health situation in Saudi Arabia. These diseases are attributed in large part to unhealthy eating habits and lack of physical activity. It is therefore necessary to rely on health education in health care centers where these centers have an important role in changing bad behaviors and reduce the burden of the spread of NCDs. Then, they have fixed the variables of age, sex, education, social status and pathological case to test the relationship between the three variables: eating habits, physical activity and health education. The results of the study showed a relationship between dietary habits, physical activity and health education, where the study indicated that women, the elderly, widows, divorcees and people with learning are more vulnerable to disease as a result of poor eating habits and lack of physical activity.

In a study conducted by Ströhle (2009) aimed to detect the relationship between physical activity and exercise, and between depression and anxiety disorders, where it is believed that physical activity and exercise have positive effects on the individual mood and anxiety, based on a systematic review of previous relevant studies. The results showed that the exercise, by patients and healthy people, contribute to the decline in the level of anxiety for them. The results showed as well as that the lower rates of depression and (some) anxiety disorders is a result of physical activity.

The purpose of the study of Caetano et al. (2007) is to detect the relationship between physical activity and urinary incontinence which is an involuntary loss of urine that occurs in women after childbirth or pregnancy. Many women let go of physical and sporting activities because of the disease that causes them embarrassment and shame and eventually influences their performance levels. The study results have shown that the physical activities and sports contribute significantly in the urinary incontinence and that woman who do not abandon their activities use some strategies to prevent urine, such as using absorbent to limit urine.

A study led by Sriskantharajah and Kai (2007) aimed to promote physical activity for women from South Asia living with coronary heart disease and diabetes, to help in the treatment of these diseases, in addition to the disclosure of the guidelines on physical activity and their influences. The study is applied to 15 women ranged from 26 to 70 years from five countries India, Pakistan, Bangladesh, Sri Lanka, East Africa and Asia, and from Hindus, Sikhs and Muslims religions. The study results showed that the beneficial use of physical activity to improve and reduce the disease is not recognized by women subject of the study. Also, the results of the study showed that the female practice of sport is due to cultural reasons. But the main reason for them is losing weight. 
The Study of Abdullah (2004) addressed the competitive sports from the point of view of some members of the Iraqi girl clubs. The study aims to know the sports concepts among members and their orientations to participation in sports and competitive activities and areas of participation. The study found that the fields of competitive sports and cultural activities recorded the highest ratio in sports concepts.

The study led by Clement et al. (2004) was designed to test the relationship between physical activity levels and attitudes, behaviors and health indicators for women. It is applied on 116 students at the American University Midwestern and whose age was between 18-24 years. The study results showed a relationship between physical activity, attitudes, behaviors and health indicators, especially eating habits. Dietary habits were associated with physical activity levels among women.

\section{Methodology}

Our study was based on the descriptive approach by reviewing the theoretical literature on the exercise of physical activities, in addition to a review of the related previous studies. The study developed the questionnaires to detect common diseases among Saudi women and their relationship with the physical activity level and some other variables. To achieve the purposes of this study, data were collected and analyzed to obtain the results that contribute to test our hypotheses and help to provide a set of recommendations based on these results.

\subsection{Sampling}

The sample of this study is intentionally selected according to a set of controls that achieve the objectives of this study; this sample consists of 1500 Saudi women. We distributed the study's tools and we collected 1327 questionnaires with the exclusion of 94 questionnaires because of the lack of relevance for the analysis. So the final number of participants in this study became 1233 Saudi women. Table 1 shows the characteristics of the study sample.

Table 1. Demographic characteristics of the individuals of the study

\begin{tabular}{|c|c|c|c|c|c|c|c|}
\hline Variabal & $\begin{array}{l}\text { Types of } \\
\text { variabal }\end{array}$ & Number & $\%$ & Variabal & Types of variabal & Number & $\%$ \\
\hline \multirow{5}{*}{$\begin{array}{l}\text { Residence } \\
\text { place }\end{array}$} & Middle & 772 & 62.6 & \multirow{6}{*}{$\begin{array}{l}\text { Approximate } \\
\text { Weight }(\mathrm{kg})\end{array}$} & $45-50$ & 303 & 24.6 \\
\hline & Eastern & 65 & 5.3 & & $51-56$ & 265 & 21.5 \\
\hline & Western & 95 & 7.7 & & $57-62$ & 222 & 18.0 \\
\hline & Northern & 46 & 3.7 & & $63-68$ & 144 & 11.7 \\
\hline & Southern & 255 & 20.7 & & $69-74$ & 112 & 9.1 \\
\hline \multirow{5}{*}{ Age group } & $18-25$ & 892 & 72.3 & & $75-79$ & 141 & 11.4 \\
\hline & $26-33$ & 155 & 12.6 & \multirow{7}{*}{$\begin{array}{l}\text { The nature of the } \\
\text { profession }\end{array}$} & 80 and more & 46 & 3.7 \\
\hline & $34-41$ & 104 & 8.4 & & Housewife & 70 & 5.7 \\
\hline & $42-51$ & 65 & 5.3 & & Teacher & 283 & 23 \\
\hline & 52 and more & 17 & 1.4 & & $\begin{array}{l}\text { Administrative } \\
\text { employee }\end{array}$ & 82 & 6.7 \\
\hline \multirow{8}{*}{$\begin{array}{l}\text { Educational } \\
\text { level }\end{array}$} & Uneducated & 6 & 0.5 & & Competent & 49 & 4 \\
\hline & $\begin{array}{l}\text { Read and do } \\
\text { not write }\end{array}$ & 14 & 1.1 & & Free works & 7 & 0.6 \\
\hline & Primary & 21 & 1.7 & & Others & 742 & 60.2 \\
\hline & medium & 3 & 0.2 & \multirow{5}{*}{ Marital status } & Single & 739 & 59.9 \\
\hline & Secondary & 187 & 15.2 & & Married & 448 & 36.3 \\
\hline & Bachelor & 971 & 78.8 & & Divorced & 40 & 3.2 \\
\hline & Master & 29 & 2.4 & & Widow & 6 & 0.5 \\
\hline & Doctorate & 2 & 0.2 & & & & \\
\hline
\end{tabular}




\subsection{Instrument}

The study developed a list of surveys to detect the common diseases among Saudi women and their relationship with physical activity level and some variables, it based on a review of the theoretical literature on women sport, in addition to access to tools that used in previous studies as a study of Merza et al. (2013), and the study of Aljalad et al. (1992). The study is in two parts; the first concerns demographic factors of the sample, while the second part contains a list of common diseases associated with low levels of sports practice.

\subsection{Statistical Treatment}

To achieve the objectives of our study we used a statistical package for Social Sciences (SPSS) to test the hypotheses of the study. We used the frequencies, the percentage and (PHI) test.

\section{Results}

The test of the first hypothesis: "There is no statistically significant relationship between common diseases among Saudi women and physiological variables (age group and weight)". To test this hypothesis the frequencies, the percentage and the PHI coefficient extracted to reveal the nature of the relationship between the common diseases among Saudi women and with age group variable, in the first time Table 2.1 and with weight Table 2.2 in a second time, showed that.

Table 2.1 shown a statistically significant relationship between the common diseases among Saudi women and with age group variable, where the value of coefficient PHI for obesity $(0.214)$, for hypertension $(0.204)$, for diabetes $(0.229)$, for cholesterol $(0.186)$ and asthma $(0.166)$. These values is with statistically significant at the significance level $(\alpha=0.05)$.

The table indicates, also, that the highest percentage among Saudi women who were between the ages of 42-51 years, where reached for the obesity (58.5\%), for cholesterol disease (46.2\%), asthma (46.2\%). While the highest proportion of women their aged between 52 years and over and that reached for hypertension $(52.9 \%)$, and diabetes $(64.7 \%)$.

The interpretation of this result is attributable for the age group that experienced by women in pregnancy, childbirth, aging, and the low of sports practice level during this age period, which reflected to the spread of common diseases among women and is obesity disease, cholesterol, and asthma, in addition to hypertension and diabetes, which form the highest percentage of women between the ages of 52 years and above.

To test the relation between the common diseases among Saudi women and with weight variable, the frequencies, the percentage and PHI coefficient are extracted to reveal this relation and Table 2.2 showed that.

Table 2.2 showed a statistically significant relationship between the common diseases among Saudi women and with weight variable, that reached the value of PHI coefficient for obesity $(0.315)$, and for hypertension (0.277), and for diabetes $(0.285)$, and for cholesterol $(0.242)$, and asthma (0.236), and these values were with statistically significant at the significance level $(\alpha=0.05)$.

And the table also indicates that the highest percentage was among Saudi women who weigh reached about 80 $\mathrm{kg}$ and above, that reached for the obesity (54.3\%), for the hypertension about $(50 \%)$, diabetes $(43.5 \%)$, cholesterol (43.5\%) and asthma (37\%). This may explain the high level of weight and unhealthy nutrition and negative habits of food among women, in light of the low level of sports practice for them.

We tested the second hypothesis as"There is no statistically significant relationship between common diseases among Saudi women and social variables (residence area, educational level, children's number, nature of the profession and social situation".

To test this hypothesis the frequencies, the percentage and coefficient link Phi are extracted to reveal the nature of the relationship between the common diseases among Saudi women and several sub-variables. We started with the area of residence variable and Table 3.1 showed the different results.

Table 3.1 showed a statistically significant relationship between the common diseases among Saudi women and with area of residence variable, where the value of PHI coefficient of obesity (0.218), for the hypertension (0.238), for diabetes $(0.222)$, for cholesterol $(0.210)$ and for asthma $(0.192)$. These values are with statistically significant at the significance level $(\alpha=0.05)$.

The table also indicates that the highest percentage was among Saudi women who live the eastern region, that reached for the obesity $(41.5 \%)$, for hypertension (38.5\%), for diabetes, cholesterol (38.5\%) and for asthma (38.5\%) for each disease. it can interpret this result of geographical factors that may have an impact in the prevalence of obesity, glycemic disease, cholesterol and asthma, in the eastern region, because of the negative 
social habits. the matter which has a role in this scientific result.

Then, to test the effect of the second social sub-variables (educational level), the frequencies, percentage and PHI coefficient are extracted in Table 3.2.

Table 3.2 showed a statistically significant relationship between the common diseases among Saudi women and with the educational level that reached the value of PHI coefficient for obesity (0.204), for hypertension (0.163), for diabetes $(0.188)$, for cholesterol $(0.177)$ and asthma (0.206). These values are with statistically significant at the significance level $(\alpha=0.05)$.

The table indicates that the highest percentage was among Saudi women that their education is medium, that reached for all diseases $(100 \%)$ and be explained this result to the average level of health awareness, a low level of motor performance and physical activity among women and the decline of cognitive of the sports practice importance to limit the spread of this disease among women.

We've tested, then, if there is a relationship between the common diseases among Saudi women and with the nature of the profession. To test this sub-hypothesis the frequencies, the percentage, and PHI coefficient are extracted to reveal the nature of the relationship between the common diseases among Saudi women and with the sub-variables "the nature of the profession". Table 3.3 showed that.

Table 3.3 showed a statistically significant relationship between the common diseases among Saudi women and the nature of the profession. That the value of PHI coefficient for obesity $(0.128)$, for hypertension $(0.148)$, for diabetes $(0.151)$, for cholesterol (0.147) and asthma (0.154). These values are a statistically significant at the significance level $(\alpha=0.05)$. The table indicates that the highest percentage was among Saudi teachers, that reached for the obesity $(32.2 \%)$, and was the highest rate among female Saudi employees where reached for hypertension (39\%), for diabetes (39\%), for cholesterol (39\%), and for asthma (41.5\%). This result is according to the nature of education and what it included of the difficulties and problems with the students and the size of the heavy work to reach the information and to search for excellence in their schools, in addition to the lack of adequate time for sports practice in light of the requirements of the educational work among teacher women.

Also, for testing the relationship between the common diseases among Saudi women and with social variables, we conducted the sub-variable "the marital status". To test this sub-hypothesis the frequencies, the percentage and PHI coefficient are extracted to reveal the nature of the relationship between the common diseases among Saudi women and with the marital status. The Table 3.4 showed that.

The Table 3.4 showed a statistically significant relationship between the common diseases among Saudi women and with the social situation that reached the value of PHI coefficient for obesity $(0.162)$, for hypertension $(0.172)$, for diabetes $(0.130)$, for cholesterol $(0.129)$ and for asthma $(0.096)$. These values are with statistically significant at the significance level $(\alpha=0.05)$. The table also indicates that the highest percentage was among found among divorced Saudi women that reached for obesity about $(52.5 \%)$, asthma (30\%). The highest rate among Saudi women widowed that reached for hypertension is $(100 \%)$, for diabetes is $(50 \%)$ and for cholesterol is $(50 \%)$.

This can due to psychological and living situation of divorced and widow woman and the lack of economic resources, which is reflected in the level of their agility and practice sports activities.

The latest social sub-variable is the children's number. To test this sub-hypothesis the frequencies, the percentage and PHI coefficient are extracted to reveal the nature of the relationship between the common diseases among Saudi women and with the number of children. The Table 3.5 showed that.

Table 3.5 showed a statistically significant relationship between obesity among Saudi women and with the variable of children number that reached the value of PHI coefficient $(0.129)$. This value was with statistically significant at the significance level $(\alpha=0.05)$ and reached the highest rate among Saudi women who have 7-8 children $(50 \%)$.

The table also indicates that there is no statistically significant relationship between the common diseases among Saudi women and with the variable of number of children that reached the value of PHI coefficient for hypertension (0.082), for diabetes (0.087), for cholesterol (0.078), and for asthma (0.063). These values are not with statistically significant at the significance level $(\alpha=0.05)$.

This can be explained due to the large number of children and the problems arising from pregnancy, childbirth, diseases that result, parental concerns and the lack of time for sport among women.

The last step is to test our third hypothesis which: "There is no statistically significant relationship between the common diseases among Saudi women and with some sportive variables. 
To get there, we start with the sub-variable of practice sports activity. To test this sub-hypothesis the frequencies, the percentage, and the PHI coefficient are extracted to reveal the nature of the relationship between the common diseases among Saudi women and with the practice of physical activity. Table 4.1 showed that.

The Table 4.1 showed a statistically significant relationship between asthma among Saudi women and with the sub-variable of practice sports activity that reached the value of PHI coefficient about $(0.080)$. This value was statistically significant at the significance level $(\alpha=0.05)$ and reached the highest rate among Saudi women who practice physical activity $(23.7 \%)$.

The table also indicates that there is no statistically significant relationship between the common diseases among Saudi women and with the variable of practice sports activity that reached the value of PHI coefficient for obesity (0.032), for hypertension (0.045), for diabetes $(0.053)$ and for cholesterol $(0.036)$. These values are not with statistically significant at the significance level $(\alpha=0.05)$.

Then we tested if there is no statistically significant relationship between the common diseases among Saudi women and with the second sportive sub-variable as the "Justification for the practice of physical activity variable". To test this sub-hypothesis the frequencies, the percentage and PHI coefficient are extracted to reveal the nature of this. The Table 4.2 showed that.

The Table 4.2 showed a statistically significant relationship between the common diseases among Saudi woman and with the justification practice of physical activity that reached the value of PHI coefficient for obesity (0.093), for hypertension (0.137), for diabetes (0.139), for cholesterol (0.130) and for asthma (0.092). These values are with statistically significant at the significance level $(\alpha=0.05)$. Also, the highest percentage was among Saudi women who suffer from a medical condition that reached for obesity $(29.6 \%)$, for hypertension $(38.3 \%)$, for diabetes $(37 \%)$, for cholesterol $(34.6 \%)$ and for asthma (33.3\%). Perhaps this result explained the full awareness of the research sample for the importance of sports practice and its role in treatment of pathological women's problems.

Finally, we tested the last sub sportive as the rate of practice of physical activity per week. To test this sub-hypothesis the frequencies, the percentage and PHI coefficient are extracted to reveal the nature of the relationship between the common diseases among Saudi women and the rate of practice of physical activity per week. The Table 4.3 showed that.

The Table 4.3 showed a statistically significant relationship between the common diseases among Saudi women and with the rate of practice sports activity per week that reached the value of PHI coefficient, for hypertension (0.081), for diabetes (0.096), for cholesterol (0.093), and for asthma (0.105). These values are with statistically significant at the significance level $(\alpha=0.05)$.

The table also indicates that the highest percentage was among Saudi women who practice the physical activity twice a week that reached for hypertension $(23.1 \%)$, for diabetes $(22.7 \%)$, for cholesterol (22.1\%) and for asthma $(23.7 \%)$. Also there is no statistically significant differences relationship between obesity among Saudi women and with the rate of practice sports activity weekly that reached the value of PHI coefficient $(0.075)$. This value was not statistically significant at the significance level $(\alpha=0.05)$ and can be explained this result because of the awareness of the research sample of the importance of continuing the sports practice and the effective role of physical activity in reducing the level of prevalence of common diseases among Saudi women.

Table 2.1. The relationship between the common diseases among Saudi women and age group variable

\begin{tabular}{llllllllllll}
\hline \multirow{2}{*}{ Age group } & \multicolumn{2}{c}{ Obesity } & \multicolumn{3}{c}{ Hypertension } & \multicolumn{2}{c}{ Diabetes } & \multicolumn{2}{c}{ Cholesterol } & \multicolumn{2}{c}{ Asthma } \\
\cline { 2 - 11 } & & Infected & Uninfected & Infected & Uninfected & Infected & Uninfected & Infected & Uninfected & Infected & Uninfected \\
\hline $18-25$ & $\mathrm{~T}$ & 177 & 715 & 143 & 749 & 137 & 755 & 143 & 749 & 162 & 730 \\
& $\%$ & $19.8 \%$ & $80.2 \%$ & $16.0 \%$ & $84.0 \%$ & $15.4 \%$ & $84.6 \%$ & $16.0 \%$ & $84.0 \%$ & $18.2 \%$ & $81.8 \%$ \\
$26-33$ & $\mathrm{~T}$ & 45 & 110 & 33 & 122 & 33 & 122 & 35 & 120 & 40 & 115 \\
& $\%$ & $29.0 \%$ & $71.0 \%$ & $21.3 \%$ & $78.7 \%$ & $21.3 \%$ & $78.7 \%$ & $22.6 \%$ & $77.4 \%$ & $25.8 \%$ & $74.2 \%$ \\
$34-41$ & $\mathrm{~T}$ & 32 & 72 & 27 & 77 & 27 & 77 & 27 & 77 & 27 & 77 \\
& $\%$ & $30.8 \%$ & $69.2 \%$ & $26.0 \%$ & $74.0 \%$ & $26.0 \%$ & $74.0 \%$ & $26.0 \%$ & $74.0 \%$ & $26.0 \%$ & $74.0 \%$ \\
$42-51$ & $\mathrm{~T}$ & 38 & 27 & 30 & 35 & 30 & 35 & 30 & 35 & 30 & 35
\end{tabular}




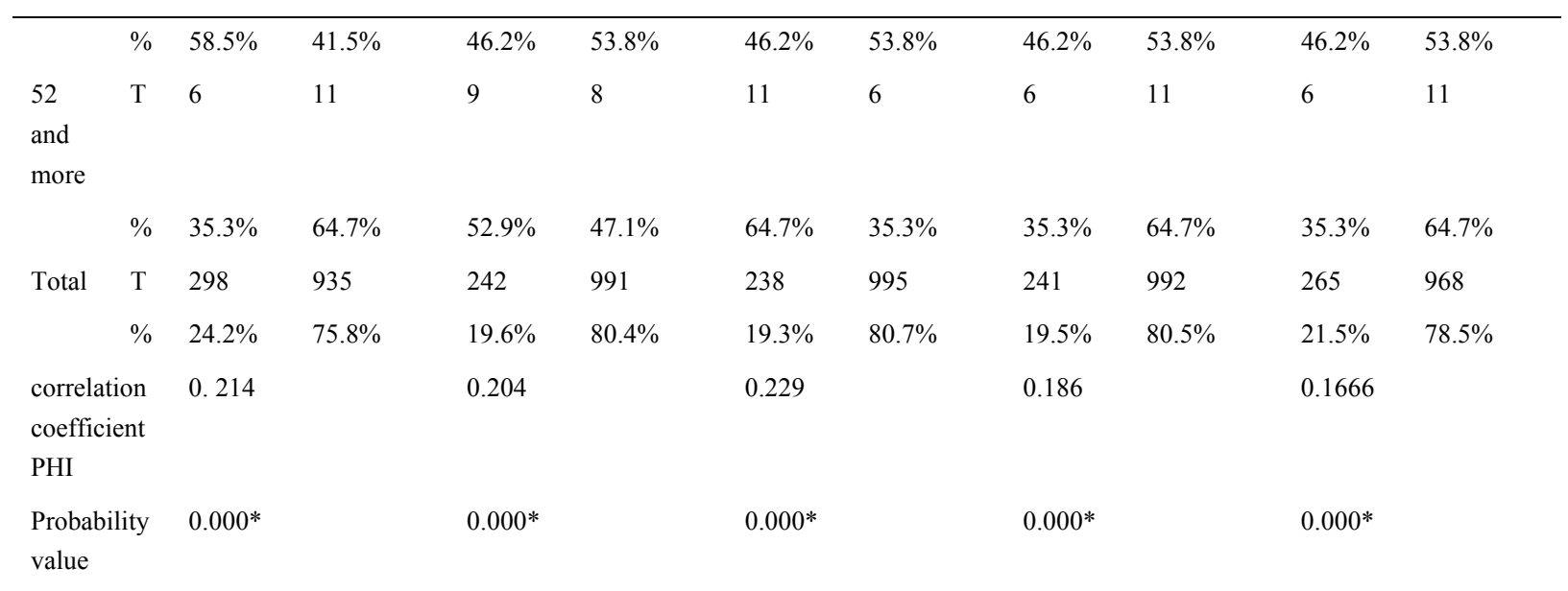

*With statistical significance at the level of significance $(\alpha=0.05)$.

Table 2.2. The relationship between the common diseases among Saudi women and with weight variable

\begin{tabular}{|c|c|c|c|c|c|c|c|c|c|c|c|}
\hline \multicolumn{2}{|l|}{ Weight(kg) } & \multicolumn{2}{|c|}{ Obesity } & \multicolumn{2}{|c|}{ hypertension } & \multicolumn{2}{|c|}{ Diabetes } & \multicolumn{2}{|c|}{ Cholesterol } & \multicolumn{2}{|c|}{ Asthma } \\
\hline & & Infected & Uninfected & Infected & Uninfected & Infected & Uninfected & Infected & Uninfected & Infected & Uninfected \\
\hline \multirow[t]{2}{*}{$45-50$} & $\mathrm{~T}$ & 21 & 282 & 18 & 285 & 18 & 285 & 21 & 282 & 26 & 277 \\
\hline & $\%$ & $6.9 \%$ & $93.1 \%$ & $5.9 \%$ & $94.1 \%$ & $5.9 \%$ & $94.1 \%$ & $6.9 \%$ & $93.1 \%$ & $8.6 \%$ & $91.4 \%$ \\
\hline \multirow[t]{2}{*}{$51-56$} & $\mathrm{~T}$ & 56 & 209 & 51 & 214 & 51 & 214 & 53 & 212 & 53 & 212 \\
\hline & $\%$ & $21.1 \%$ & $78.9 \%$ & $19.2 \%$ & $80.8 \%$ & $19.2 \%$ & $80.8 \%$ & $20.0 \%$ & $80.0 \%$ & $20.0 \%$ & $80.0 \%$ \\
\hline \multirow[t]{2}{*}{$57-62$} & $\mathrm{~T}$ & 44 & 178 & 34 & 188 & 34 & 188 & 37 & 185 & 42 & 180 \\
\hline & $\%$ & $19.8 \%$ & $80.2 \%$ & $15.3 \%$ & $84.7 \%$ & $15.3 \%$ & $84.7 \%$ & $16.7 \%$ & $83.3 \%$ & $18.9 \%$ & $81.1 \%$ \\
\hline \multirow[t]{2}{*}{$63-68$} & $\mathrm{~T}$ & 48 & 96 & 40 & 104 & 42 & 102 & 40 & 104 & 42 & 102 \\
\hline & $\%$ & $33.3 \%$ & $66.7 \%$ & $27.8 \%$ & $72.2 \%$ & $29.2 \%$ & $70.8 \%$ & $27.8 \%$ & $72.2 \%$ & $29.2 \%$ & $70.8 \%$ \\
\hline \multirow[t]{2}{*}{$69-74$} & $\mathrm{~T}$ & 49 & 63 & 26 & 86 & 26 & 86 & 23 & 89 & 31 & 81 \\
\hline & $\%$ & $43.8 \%$ & $56.3 \%$ & $23.2 \%$ & $76.8 \%$ & $23.2 \%$ & $76.8 \%$ & $20.5 \%$ & $79.5 \%$ & $27.7 \%$ & $72.3 \%$ \\
\hline \multirow[t]{2}{*}{$75-79$} & $\mathrm{~T}$ & 55 & 86 & 50 & 91 & 47 & 94 & 47 & 94 & 54 & 87 \\
\hline & $\%$ & $39.0 \%$ & $61.0 \%$ & $35.5 \%$ & $64.5 \%$ & $33.3 \%$ & $66.7 \%$ & $33.3 \%$ & $66.7 \%$ & $38.3 \%$ & $61.7 \%$ \\
\hline \multirow{3}{*}{$\begin{array}{l}80 \quad \text { and } \\
\text { more }\end{array}$} & $\mathrm{T}$ & 25 & 21 & 23 & 23 & 20 & 26 & 20 & 26 & 17 & 29 \\
\hline & & & & & & & & & & & \\
\hline & $\%$ & $54.3 \%$ & $45.7 \%$ & $50.0 \%$ & $50.0 \%$ & $43.5 \%$ & $56.5 \%$ & $43.5 \%$ & $56.5 \%$ & $37.0 \%$ & $63.0 \%$ \\
\hline \multirow[t]{2}{*}{ Total } & $\mathrm{T}$ & 298 & 935 & 242 & 991 & 238 & 995 & 241 & 992 & 265 & 968 \\
\hline & $\%$ & $24.2 \%$ & $75.8 \%$ & $19.6 \%$ & $80.4 \%$ & $19.3 \%$ & $80.7 \%$ & $19.5 \%$ & $80.5 \%$ & $21.5 \%$ & $78.5 \%$ \\
\hline \multicolumn{2}{|c|}{$\begin{array}{l}\text { Correlation } \\
\text { coefficient PHI }\end{array}$} & \multicolumn{2}{|c|}{0.315} & \multicolumn{2}{|c|}{0.277} & \multicolumn{2}{|c|}{0.285} & \multicolumn{2}{|c|}{0.242} & \multicolumn{2}{|c|}{0.236} \\
\hline \multicolumn{2}{|c|}{ Probability value } & \multicolumn{2}{|c|}{$0.000 *$} & \multicolumn{2}{|c|}{$0.000 *$} & \multicolumn{2}{|c|}{$0.000 *$} & \multicolumn{2}{|c|}{$0.000 *$} & \multicolumn{2}{|c|}{$0.000 *$} \\
\hline
\end{tabular}

*With statistical significance at the level of significance $(\alpha=0.05)$. 
Table 3.1. The relationship between the common diseases among Saudi women and the area of residence variable

\begin{tabular}{|c|c|c|c|c|c|c|c|c|c|c|c|}
\hline \multirow{2}{*}{\multicolumn{2}{|c|}{ Place of residence }} & \multicolumn{2}{|c|}{ Obesity } & \multicolumn{2}{|c|}{ hypertension } & \multicolumn{2}{|c|}{ Diabetes } & \multicolumn{2}{|c|}{ Cholesterol } & \multicolumn{2}{|c|}{ Asthma } \\
\hline & & Infected & Uninfected & Infected & Uninfected & Infected & Uninfected & Infected & Uninfected & Infected & Uninfected \\
\hline \multirow[t]{2}{*}{ Middle } & $\mathrm{T}$ & 168 & 604 & 127 & 645 & 129 & 643 & 135 & 637 & 153 & 619 \\
\hline & $\%$ & $21.8 \%$ & $78.2 \%$ & $16.5 \%$ & $83.5 \%$ & $16.7 \%$ & $83.3 \%$ & $17.5 \%$ & $82.5 \%$ & $19.8 \%$ & $80.2 \%$ \\
\hline \multirow[t]{2}{*}{ Eastern } & $\mathrm{T}$ & 27 & 38 & 25 & 40 & 25 & 40 & 25 & 40 & 25 & 40 \\
\hline & $\%$ & $41.5 \%$ & $58.5 \%$ & $38.5 \%$ & $61.5 \%$ & $38.5 \%$ & $61.5 \%$ & $38.5 \%$ & $61.5 \%$ & $38.5 \%$ & $61.5 \%$ \\
\hline \multirow[t]{2}{*}{ Western } & $\mathrm{T}$ & 10 & 85 & 6 & 89 & 6 & 89 & 6 & 89 & 9 & 86 \\
\hline & $\%$ & $10.5 \%$ & $89.5 \%$ & $6.3 \%$ & $93.7 \%$ & $6.3 \%$ & $93.7 \%$ & $6.3 \%$ & $93.7 \%$ & $9.5 \%$ & $90.5 \%$ \\
\hline \multirow[t]{2}{*}{ Northern } & $\mathrm{T}$ & 0 & 46 & 0 & 46 & 0 & 46 & 0 & 46 & 0 & 46 \\
\hline & $\%$ & $.0 \%$ & $100.0 \%$ & $.0 \%$ & $100.0 \%$ & $.0 \%$ & $100.0 \%$ & $.0 \%$ & $100.0 \%$ & $.0 \%$ & $100.0 \%$ \\
\hline \multirow[t]{2}{*}{ Southern } & $\mathrm{T}$ & 93 & 162 & 84 & 171 & 78 & 177 & 75 & 180 & 78 & 177 \\
\hline & $\%$ & $36.5 \%$ & $63.5 \%$ & $32.9 \%$ & $67.1 \%$ & $30.6 \%$ & $69.4 \%$ & $29.4 \%$ & $70.6 \%$ & $30.6 \%$ & $69.4 \%$ \\
\hline \multirow[t]{2}{*}{ Total } & $\mathrm{T}$ & 298 & 935 & 242 & 991 & 238 & 995 & 241 & 992 & 265 & 968 \\
\hline & $\%$ & $24.2 \%$ & $75.8 \%$ & $19.6 \%$ & $80.4 \%$ & $19.3 \%$ & $80.7 \%$ & $19.5 \%$ & $80.5 \%$ & $21.5 \%$ & $78.5 \%$ \\
\hline \multicolumn{2}{|c|}{$\begin{array}{l}\text { Correlation } \\
\text { coefficient PHI }\end{array}$} & \multicolumn{2}{|c|}{0.218} & \multicolumn{2}{|c|}{0.238} & \multicolumn{2}{|c|}{0.222} & \multicolumn{2}{|c|}{0.210} & \multicolumn{2}{|c|}{0.192} \\
\hline \multicolumn{2}{|c|}{ Probability value } & \multicolumn{2}{|c|}{$0.000^{*}$} & \multicolumn{2}{|c|}{$0.000 *$} & \multicolumn{2}{|c|}{$0.000^{*}$} & \multicolumn{2}{|c|}{$0.000^{*}$} & \multicolumn{2}{|c|}{$0.000 *$} \\
\hline
\end{tabular}

*With statistical significance at the level of significance $(\alpha=0.05)$.

Table 3.2. The relationship between the common diseases among Saudi women and with a variable level of education

\begin{tabular}{|c|c|c|c|c|c|c|c|c|c|c|c|}
\hline \multicolumn{2}{|c|}{ Educational level } & \multicolumn{2}{|c|}{ Obesity } & \multicolumn{2}{|c|}{ Hypertension } & \multicolumn{2}{|c|}{ Diabetes } & \multicolumn{2}{|c|}{ Cholesterol } & \multicolumn{2}{|c|}{ Asthma } \\
\hline & & Infected & Uninfected & Infected & Uninfected & Infected & Uninfected & Infected & Uninfected & Infected & Uninfected \\
\hline \multirow[t]{2}{*}{ Uneducated } & $\mathrm{T}$ & 3 & 3 & 3 & 3 & 0 & 6 & 0 & 6 & 0 & 6 \\
\hline & $\%$ & $50.0 \%$ & $50.0 \%$ & $50.0 \%$ & $50.0 \%$ & $.0 \%$ & $100.0 \%$ & $.0 \%$ & $100.0 \%$ & $.0 \%$ & $100.0 \%$ \\
\hline \multirow{2}{*}{$\begin{array}{l}\text { Read and do } \\
\text { not write }\end{array}$} & $\mathrm{T}$ & 8 & 6 & 5 & 9 & 8 & 6 & 5 & 9 & 8 & 6 \\
\hline & $\%$ & $57.1 \%$ & $42.9 \%$ & $35.7 \%$ & $64.3 \%$ & $57.1 \%$ & $42.9 \%$ & $35.7 \%$ & $64.3 \%$ & $57.1 \%$ & $42.9 \%$ \\
\hline \multirow[t]{2}{*}{ Primary } & $\mathrm{T}$ & 0 & 21 & 3 & 18 & 3 & 18 & 3 & 18 & 0 & 21 \\
\hline & $\%$ & $.0 \%$ & $100.0 \%$ & $14.3 \%$ & $85.7 \%$ & $14.3 \%$ & $85.7 \%$ & $14.3 \%$ & $85.7 \%$ & $.0 \%$ & $100.0 \%$ \\
\hline \multirow[t]{2}{*}{ Medium } & $\mathrm{T}$ & 3 & 0 & 0 & 3 & 0 & 3 & 0 & 3 & 0 & 3 \\
\hline & $\%$ & $100.0 \%$ & $.0 \%$ & $.0 \%$ & $100.0 \%$ & $.0 \%$ & $100.0 \%$ & $.0 \%$ & $100.0 \%$ & $.0 \%$ & $100.0 \%$ \\
\hline \multirow[t]{2}{*}{ Secondary } & $\mathrm{T}$ & 71 & 116 & 61 & 126 & 61 & 126 & 63 & 124 & 67 & 120 \\
\hline & $\%$ & $38.0 \%$ & $62.0 \%$ & $32.6 \%$ & $67.4 \%$ & $32.6 \%$ & $67.4 \%$ & $33.7 \%$ & $66.3 \%$ & $35.8 \%$ & $64.2 \%$ \\
\hline \multirow[t]{2}{*}{ Bachelor } & $\mathrm{T}$ & 208 & 763 & 167 & 804 & 164 & 807 & 170 & 801 & 190 & 781 \\
\hline & $\%$ & $21.4 \%$ & $78.6 \%$ & $17.2 \%$ & $82.8 \%$ & $16.9 \%$ & $83.1 \%$ & $17.5 \%$ & $82.5 \%$ & $19.6 \%$ & $80.4 \%$ \\
\hline \multirow[t]{2}{*}{ Master } & $\mathrm{T}$ & 5 & 24 & 3 & 26 & 2 & 27 & 0 & 29 & 0 & 29 \\
\hline & $\%$ & $17.2 \%$ & $82.8 \%$ & $10.3 \%$ & $89.7 \%$ & $6.9 \%$ & $93.1 \%$ & $.0 \%$ & $100.0 \%$ & $.0 \%$ & $100.0 \%$ \\
\hline \multirow[t]{2}{*}{ Doctorate } & $\mathrm{T}$ & 0 & 2 & 0 & 2 & 0 & 2 & 0 & 2 & 0 & 2 \\
\hline & $\%$ & $.0 \%$ & $100.0 \%$ & $.0 \%$ & $100.0 \%$ & $.0 \%$ & $100.0 \%$ & $.0 \%$ & $100.0 \%$ & $.0 \%$ & $100.0 \%$ \\
\hline Total & $\mathrm{T}$ & 298 & 935 & 242 & 991 & 238 & 995 & 241 & 992 & 265 & 968 \\
\hline
\end{tabular}




\begin{tabular}{|c|c|c|c|c|c|c|c|c|c|c|}
\hline$\%$ & $24.2 \%$ & $75.8 \%$ & $19.6 \%$ & $80.4 \%$ & $19.3 \%$ & $80.7 \%$ & $19.5 \%$ & $80.5 \%$ & $21.5 \%$ & $78.5 \%$ \\
\hline $\begin{array}{l}\text { Correlation } \\
\text { coefficient PHI }\end{array}$ & \multicolumn{2}{|c|}{0.204} & \multicolumn{2}{|c|}{0.163} & \multicolumn{2}{|c|}{0.188} & \multicolumn{2}{|c|}{0.177} & \multicolumn{2}{|c|}{0.206} \\
\hline Probability value & \multicolumn{2}{|c|}{$0.000 *$} & & & \multicolumn{2}{|c|}{$0.000 *$} & \multicolumn{2}{|c|}{$0.000^{*}$} & \multicolumn{2}{|c|}{$0.000^{*}$} \\
\hline
\end{tabular}

*With statistical significance at the level of significance $(\alpha=0.05)$.

Table 3.3. The relationship between the common diseases among Saudi women and with the nature of the profession

\begin{tabular}{|c|c|c|c|c|c|c|c|c|c|c|c|}
\hline \multirow{2}{*}{$\begin{array}{l}\text { The nature of } \\
\text { profession }\end{array}$} & \multirow{2}{*}{ the } & \multicolumn{2}{|l|}{ Obesity } & \multicolumn{2}{|c|}{ Hypertension } & \multicolumn{2}{|l|}{ Diabetes } & \multicolumn{2}{|c|}{ Cholesterol } & \multicolumn{2}{|l|}{ Asthma } \\
\hline & & Infected & uninfected & Infected & uninfected & Infected & uninfected & Infected & uninfected & Infected & uninfected \\
\hline \multirow[t]{2}{*}{ Housewife } & $\mathrm{T}$ & 12 & 58 & 18 & 52 & 18 & 52 & 18 & 52 & 15 & 55 \\
\hline & $\%$ & $17.1 \%$ & $82.9 \%$ & $25.7 \%$ & $74.3 \%$ & $25.7 \%$ & $74.3 \%$ & $25.7 \%$ & $74.3 \%$ & $21.4 \%$ & $78.6 \%$ \\
\hline \multirow[t]{2}{*}{ Teacher } & $\mathrm{T}$ & 91 & 192 & 54 & 229 & 51 & 232 & 50 & 233 & 57 & 226 \\
\hline & $\%$ & $32.2 \%$ & $67.8 \%$ & $19.1 \%$ & $80.9 \%$ & $18.0 \%$ & $82.0 \%$ & $17.7 \%$ & $82.3 \%$ & $20.1 \%$ & $79.9 \%$ \\
\hline \multirow[t]{2}{*}{ Employee } & $\mathrm{T}$ & 26 & 56 & 32 & 50 & 32 & 50 & 32 & 50 & 34 & 48 \\
\hline & $\%$ & $31.7 \%$ & $68.3 \%$ & $39.0 \%$ & $61.0 \%$ & $39.0 \%$ & $61.0 \%$ & $39.0 \%$ & $61.0 \%$ & $41.5 \%$ & $58.5 \%$ \\
\hline \multirow[t]{2}{*}{ Competent } & $\mathrm{T}$ & 12 & 37 & 12 & 37 & 12 & 37 & 12 & 37 & 17 & 32 \\
\hline & $\%$ & $24.5 \%$ & $75.5 \%$ & $24.5 \%$ & $75.5 \%$ & $24.5 \%$ & $75.5 \%$ & $24.5 \%$ & $75.5 \%$ & $34.7 \%$ & $65.3 \%$ \\
\hline \multirow[t]{2}{*}{ Free works } & $\mathrm{T}$ & 0 & 7 & 0 & 7 & 0 & 7 & 0 & 7 & 0 & 7 \\
\hline & $\%$ & $.0 \%$ & $100.0 \%$ & $.0 \%$ & $100.0 \%$ & $.0 \%$ & $100.0 \%$ & $.0 \%$ & $100.0 \%$ & $.0 \%$ & $100.0 \%$ \\
\hline \multirow[t]{2}{*}{ others } & $\mathrm{T}$ & 157 & 585 & 126 & 616 & 125 & 617 & 129 & 613 & 142 & 600 \\
\hline & $\%$ & $21.2 \%$ & $78.8 \%$ & $17.0 \%$ & $83.0 \%$ & $16.8 \%$ & $83.2 \%$ & $17.4 \%$ & $82.6 \%$ & $19.1 \%$ & $80.9 \%$ \\
\hline \multirow[t]{2}{*}{ total } & $\mathrm{T}$ & 298 & 935 & 242 & 991 & 238 & 995 & 241 & 992 & 265 & 968 \\
\hline & $\%$ & $24.2 \%$ & $75.8 \%$ & $19.6 \%$ & $80.4 \%$ & $19.3 \%$ & $80.7 \%$ & $19.5 \%$ & $80.5 \%$ & $21.5 \%$ & $78.5 \%$ \\
\hline $\begin{array}{l}\text { Correlation } \\
\text { coefficient PHI }\end{array}$ & & 0.128 & & 0.148 & & 0.151 & & 0.147 & & 0.154 & \\
\hline Probability value & & $* 0.001$ & & $0.000 *$ & & $0.000 *$ & & $0.000^{*}$ & & $0.000 *$ & \\
\hline
\end{tabular}

*With statistical significance at the level of significance $(\alpha=0.05)$.

Table 3.4. The relationship between the common diseases among Saudi women and with the marital status

\begin{tabular}{|c|c|c|c|c|c|c|c|c|c|c|c|}
\hline \multirow{2}{*}{\multicolumn{2}{|c|}{ Material status }} & \multicolumn{2}{|c|}{ Obesity } & \multicolumn{2}{|c|}{ Hypertension } & \multicolumn{2}{|c|}{ Diabetes } & \multicolumn{2}{|c|}{ cholesterol } & \multicolumn{2}{|c|}{ Asthma } \\
\hline & & Infected & uninfected & Infected & uninfected & Infected & uninfected & Infected & uninfected & Infected & Uninfected \\
\hline \multirow[t]{2}{*}{ Single } & $\mathrm{T}$ & 147 & 592 & 120 & 619 & 114 & 625 & 116 & 623 & 138 & 601 \\
\hline & $\%$ & $19.9 \%$ & $80.1 \%$ & $16.2 \%$ & $83.8 \%$ & $15.4 \%$ & $84.6 \%$ & $15.7 \%$ & $84.3 \%$ & $18.7 \%$ & $81.3 \%$ \\
\hline \multirow[t]{2}{*}{ Married } & $\mathrm{T}$ & 130 & 318 & 104 & 344 & 109 & 339 & 110 & 338 & 115 & 333 \\
\hline & $\%$ & $29.0 \%$ & $71.0 \%$ & $23.2 \%$ & $76.8 \%$ & $24.3 \%$ & $75.7 \%$ & $24.6 \%$ & $75.4 \%$ & $25.7 \%$ & $74.3 \%$ \\
\hline \multirow[t]{2}{*}{ Divorced } & $\mathrm{T}$ & 21 & 19 & 12 & 28 & 12 & 28 & 12 & 28 & 12 & 28 \\
\hline & $\%$ & $52.5 \%$ & $47.5 \%$ & $30.0 \%$ & $70.0 \%$ & $30.0 \%$ & $70.0 \%$ & $30.0 \%$ & $70.0 \%$ & $30.0 \%$ & $70.0 \%$ \\
\hline \multirow[t]{2}{*}{ Widow } & $\mathrm{T}$ & 0 & 6 & 6 & 0 & 3 & 3 & 3 & 3 & 0 & 6 \\
\hline & $\%$ & $.0 \%$ & $100.0 \%$ & $100.0 \%$ & $.0 \%$ & $50.0 \%$ & $50.0 \%$ & $50.0 \%$ & $50.0 \%$ & $.0 \%$ & $100.0 \%$ \\
\hline \multirow[t]{2}{*}{ Total } & $\mathrm{T}$ & 298 & 935 & 242 & 991 & 238 & 995 & 241 & 992 & 265 & 968 \\
\hline & $\%$ & $24.2 \%$ & $75.8 \%$ & $19.6 \%$ & $80.4 \%$ & $19.3 \%$ & $80.7 \%$ & $19.5 \%$ & $80.5 \%$ & $21.5 \%$ & $78.5 \%$ \\
\hline
\end{tabular}




\begin{tabular}{|c|c|c|c|c|c|}
\hline $\begin{array}{l}\text { Correlation } \\
\text { coefficient PHI }\end{array}$ & 0.162 & 0.172 & 0.130 & 0.129 & 0.096 \\
\hline Probability value & $* 0.000$ & $* 0.000$ & $* 0.000$ & $* 0.000$ & $* 0.009$ \\
\hline
\end{tabular}

*With statistical significance at the level of significance $(\alpha=0.05)$.

Table 3.5. The relationship between the common diseases among Saudi women and with the number of children

\begin{tabular}{|c|c|c|c|c|c|c|c|c|c|c|c|}
\hline \multirow{2}{*}{ Kids numbe } & & \multicolumn{2}{|c|}{ obesity } & \multicolumn{2}{|c|}{ hypertension } & \multicolumn{2}{|c|}{ diabetes } & \multicolumn{2}{|c|}{ Cholesterol } & \multicolumn{2}{|c|}{ Asthma } \\
\hline & & infected & $\begin{array}{c}\text { not } \\
\text { infected }\end{array}$ & infected & $\begin{array}{c}\text { not } \\
\text { infected }\end{array}$ & infected & $\begin{array}{c}\text { Not } \\
\text { infected }\end{array}$ & infected & $\begin{array}{c}\text { Not } \\
\text { infected }\end{array}$ & infected & $\begin{array}{c}\text { Not } \\
\text { infected }\end{array}$ \\
\hline \multirow[t]{2}{*}{ girl } & $\mathrm{T}$ & 70 & 292 & 63 & 299 & 57 & 305 & 60 & 302 & 64 & 298 \\
\hline & $\%$ & $19.3 \%$ & $80.7 \%$ & $17.4 \%$ & $82.6 \%$ & $15.7 \%$ & $84.3 \%$ & $16.6 \%$ & $83.4 \%$ & $17.7 \%$ & $82.3 \%$ \\
\hline \multirow[t]{2}{*}{ Not exist } & $\mathrm{T}$ & 129 & 438 & 109 & 458 & 112 & 455 & 111 & 456 & 134 & 433 \\
\hline & $\%$ & $22.8 \%$ & $77.2 \%$ & $19.2 \%$ & $80.8 \%$ & $19.8 \%$ & $80.2 \%$ & $19.6 \%$ & $80.4 \%$ & $23.6 \%$ & $76.4 \%$ \\
\hline \multirow[t]{2}{*}{$2-1$} & $\mathrm{~T}$ & 45 & 98 & 31 & 112 & 31 & 112 & 34 & 109 & 31 & 112 \\
\hline & $\%$ & $31.5 \%$ & $68.5 \%$ & $21.7 \%$ & $78.3 \%$ & $21.7 \%$ & $78.3 \%$ & $23.8 \%$ & $76.2 \%$ & $21.7 \%$ & $78.3 \%$ \\
\hline \multirow[t]{2}{*}{$4-3$} & $\mathrm{~T}$ & 28 & 67 & 18 & 77 & 18 & 77 & 18 & 77 & 21 & 74 \\
\hline & $\%$ & $29.5 \%$ & $70.5 \%$ & $18.9 \%$ & $81.1 \%$ & $18.9 \%$ & $81.1 \%$ & $18.9 \%$ & $81.1 \%$ & $22.1 \%$ & $77.9 \%$ \\
\hline \multirow[t]{2}{*}{$6-7$} & $\mathrm{~T}$ & 18 & 32 & 15 & 35 & 14 & 36 & 12 & 38 & 12 & 38 \\
\hline & $\%$ & $36.0 \%$ & $64.0 \%$ & $30.0 \%$ & $70.0 \%$ & $28.0 \%$ & $72.0 \%$ & $24.0 \%$ & $76.0 \%$ & $24.0 \%$ & $76.0 \%$ \\
\hline \multirow[t]{2}{*}{$8-7$} & $\mathrm{~T}$ & 8 & 8 & 6 & 10 & 6 & 10 & 6 & 10 & 3 & 13 \\
\hline & $\%$ & $50.0 \%$ & $50.0 \%$ & $37.5 \%$ & $62.5 \%$ & $37.5 \%$ & $62.5 \%$ & $37.5 \%$ & $62.5 \%$ & $18.8 \%$ & $81.3 \%$ \\
\hline \multirow[t]{2}{*}{ total } & $\mathrm{T}$ & 298 & 935 & 242 & 991 & 238 & 995 & 241 & 992 & 265 & 968 \\
\hline & $\%$ & $24.2 \%$ & $75.8 \%$ & $19.6 \%$ & $80.4 \%$ & $19.3 \%$ & $80.7 \%$ & $19.5 \%$ & $80.5 \%$ & $21.5 \%$ & $78.5 \%$ \\
\hline \multicolumn{2}{|c|}{$\begin{array}{l}\text { PHI correlation } \\
\text { coefficient }\end{array}$} & \multicolumn{2}{|c|}{0,129} & \multicolumn{2}{|c|}{0,082} & \multicolumn{2}{|c|}{0,087} & \multicolumn{2}{|c|}{0,078} & \multicolumn{2}{|c|}{0,063} \\
\hline \multicolumn{2}{|c|}{ Total value } & \multicolumn{2}{|c|}{$* 0,001$} & \multicolumn{2}{|c|}{0,143} & \multicolumn{2}{|c|}{0,095} & \multicolumn{2}{|c|}{0,180} & \multicolumn{2}{|c|}{0,423} \\
\hline
\end{tabular}

*With statistical significance at the level of significance $(\alpha=0.05)$.

Table 4.1. The relationship between the common diseases among Saudi women and the practice sports activity

\begin{tabular}{|c|c|c|c|c|c|c|c|c|c|c|c|}
\hline \multirow{2}{*}{$\begin{array}{l}\text { Practice } \\
\text { activity }\end{array}$} & \multirow{2}{*}{ sports } & \multicolumn{2}{|c|}{ Obesity } & \multicolumn{2}{|c|}{ Hypertension } & \multicolumn{2}{|c|}{ Diabetes } & \multicolumn{2}{|c|}{ Cholesterol } & \multicolumn{2}{|c|}{ Asthma } \\
\hline & & Infected & uninfected & Infected & uninfected & Infected & uninfected & Infected & uninfected & Infected & Uninfected \\
\hline \multirow[t]{2}{*}{ No } & $\mathrm{T}$ & 61 & 213 & 47 & 227 & 44 & 230 & 49 & 225 & 43 & 231 \\
\hline & $\%$ & $22.3 \%$ & $77.7 \%$ & $17.2 \%$ & $82.8 \%$ & $16.1 \%$ & $83.9 \%$ & $17.9 \%$ & $82.1 \%$ & $15.7 \%$ & $84.3 \%$ \\
\hline \multirow[t]{2}{*}{ Sometimes } & $\mathrm{T}$ & 202 & 600 & 168 & 634 & 167 & 635 & 165 & 637 & 190 & 612 \\
\hline & $\%$ & $25.2 \%$ & $74.8 \%$ & $20.9 \%$ & $79.1 \%$ & $20.8 \%$ & $79.2 \%$ & $20.6 \%$ & $79.4 \%$ & $23.7 \%$ & $76.3 \%$ \\
\hline \multirow[t]{2}{*}{ Yes } & $\mathrm{T}$ & 35 & 122 & 27 & 130 & 27 & 130 & 27 & 130 & 32 & 125 \\
\hline & $\%$ & $22.3 \%$ & $77.7 \%$ & $17.2 \%$ & $82.8 \%$ & $17.2 \%$ & $82.8 \%$ & $17.2 \%$ & $82.8 \%$ & $20.4 \%$ & $79.6 \%$ \\
\hline \multirow[t]{2}{*}{ Total } & $\mathrm{T}$ & 298 & 935 & 242 & 991 & 238 & 995 & 241 & 992 & 265 & 968 \\
\hline & $\%$ & $24.2 \%$ & $75.8 \%$ & $19.6 \%$ & $80.4 \%$ & $19.3 \%$ & $80.7 \%$ & $19.5 \%$ & $80.5 \%$ & $21.5 \%$ & $78.5 \%$ \\
\hline \multicolumn{2}{|c|}{$\begin{array}{l}\text { correlation } \\
\text { coefficient PHI }\end{array}$} & \multicolumn{2}{|c|}{0.032} & \multicolumn{2}{|c|}{0.045} & \multicolumn{2}{|c|}{0.053} & \multicolumn{2}{|c|}{0.036} & \multicolumn{2}{|c|}{0.080} \\
\hline \multicolumn{2}{|c|}{ Probability value } & \multicolumn{2}{|c|}{0.523} & \multicolumn{2}{|c|}{0.281} & \multicolumn{2}{|c|}{0.175} & \multicolumn{2}{|c|}{0.456} & \multicolumn{2}{|c|}{$0.020^{*}$} \\
\hline
\end{tabular}


*With statistical significance at the level of significance $(\alpha=0.05)$.

Table 4.2. The relationship between the common diseases among Saudi women and with the Justification for the practice of physical activity variable

\begin{tabular}{|c|c|c|c|c|c|c|c|c|c|c|c|}
\hline \multirow{2}{*}{\multicolumn{2}{|c|}{$\begin{array}{l}\text { Justifications of the } \\
\text { practice of sports } \\
\text { activity }\end{array}$}} & \multicolumn{2}{|c|}{ Obesity } & \multicolumn{2}{|c|}{ Hypertension } & \multicolumn{2}{|c|}{ Diabetes } & \multicolumn{2}{|c|}{ Cholesterol } & \multicolumn{2}{|c|}{ Asthma } \\
\hline & & infected & uninfected & infected & uninfected & infected & uninfected & infected & uninfected & infected & uninfected \\
\hline \multirow[t]{2}{*}{ Usually } & $\mathrm{T}$ & 57 & 148 & 46 & 159 & 49 & 156 & 52 & 153 & 51 & 154 \\
\hline & $\%$ & $27.8 \%$ & $72.2 \%$ & $22.4 \%$ & $77.6 \%$ & $23.9 \%$ & $76.1 \%$ & $25.4 \%$ & $74.6 \%$ & $24.9 \%$ & $75.1 \%$ \\
\hline \multirow[t]{2}{*}{ Fitness } & $\mathrm{T}$ & 174 & 518 & 127 & 565 & 121 & 571 & 123 & 569 & 132 & 560 \\
\hline & $\%$ & $25.1 \%$ & $74.9 \%$ & $18.4 \%$ & $81.6 \%$ & $17.5 \%$ & $82.5 \%$ & $17.8 \%$ & $82.2 \%$ & $19.1 \%$ & $80.9 \%$ \\
\hline \multirow[t]{2}{*}{$\begin{array}{l}\text { Satisfactory } \\
\text { condition }\end{array}$} & $\mathrm{T}$ & 24 & 57 & 31 & 50 & 30 & 51 & 28 & 53 & 27 & 54 \\
\hline & $\%$ & $29.6 \%$ & $70.4 \%$ & $38.3 \%$ & $61.7 \%$ & $37.0 \%$ & $63.0 \%$ & $34.6 \%$ & $65.4 \%$ & $33.3 \%$ & $66.7 \%$ \\
\hline \multirow[t]{2}{*}{$\begin{array}{l}\text { Entertainment } \\
\text { Promotion }\end{array}$} & $\mathrm{T}$ & 43 & 212 & 38 & 217 & 38 & 217 & 38 & 217 & 55 & 200 \\
\hline & $\%$ & $16.9 \%$ & $83.1 \%$ & $14.9 \%$ & $85.1 \%$ & $14.9 \%$ & $85.1 \%$ & $14.9 \%$ & $85.1 \%$ & $21.6 \%$ & $78.4 \%$ \\
\hline \multirow[t]{2}{*}{ Total } & $\mathrm{T}$ & 298 & 935 & 242 & 991 & 238 & 995 & 241 & 992 & 265 & 968 \\
\hline & $\%$ & $24.2 \%$ & $75.8 \%$ & $19.6 \%$ & $80.4 \%$ & $19.3 \%$ & $80.7 \%$ & $19.5 \%$ & $80.5 \%$ & $21.5 \%$ & $78.5 \%$ \\
\hline $\begin{array}{l}\text { Correlation } \\
\text { coefficient PHI }\end{array}$ & & \multicolumn{2}{|c|}{0.093} & \multicolumn{2}{|c|}{0.137} & \multicolumn{2}{|c|}{0.139} & \multicolumn{2}{|c|}{0.130} & \multicolumn{2}{|c|}{0.092} \\
\hline Probability value & & \multicolumn{2}{|c|}{$0.014 *$} & \multicolumn{2}{|c|}{$0.000 *$} & \multicolumn{2}{|c|}{$0.000 *$} & \multicolumn{2}{|c|}{$0.000 *$} & \multicolumn{2}{|c|}{$0.015^{*}$} \\
\hline
\end{tabular}

*With statistical significance at the level of significance $(\alpha=0.05)$.

Table 4.3. The relationship between the common diseases among Saudi women and with the rate of practice of physical activity per week

\begin{tabular}{|c|c|c|c|c|c|c|c|c|c|c|c|}
\hline \multirow{2}{*}{\multicolumn{2}{|c|}{$\begin{array}{l}\text { The rate of practice } \\
\text { the physical } \\
\text { activity per week }\end{array}$}} & \multicolumn{2}{|c|}{ Obesity } & \multicolumn{2}{|c|}{ Hypertension } & \multicolumn{2}{|c|}{ Diabetes } & \multicolumn{2}{|c|}{ Cholesterol } & \multicolumn{2}{|c|}{ Asthma } \\
\hline & & \multirow{2}{*}{$\begin{array}{c}\text { infected } \\
150\end{array}$} & \multirow{2}{*}{$\begin{array}{c}\text { Uninfected } \\
479\end{array}$} & \multirow{2}{*}{$\frac{\text { infected }}{121}$} & \multirow{2}{*}{$\begin{array}{c}\text { Uninfected } \\
508\end{array}$} & \multirow{2}{*}{$\frac{\text { infected }}{124}$} & \multirow{2}{*}{$\begin{array}{c}\text { Uninfected } \\
505\end{array}$} & \multirow{2}{*}{$\frac{\text { infected }}{126}$} & \multirow{2}{*}{$\begin{array}{c}\text { Uninfected } \\
503\end{array}$} & \multirow{2}{*}{$\frac{\text { infected }}{144}$} & \multirow{2}{*}{$\begin{array}{c}\text { Uninfected } \\
485\end{array}$} \\
\hline once & $\mathrm{T}$ & & & & & & & & & & \\
\hline & $\%$ & $23.8 \%$ & $76.2 \%$ & $19.2 \%$ & $80.8 \%$ & $19.7 \%$ & $80.3 \%$ & $20.0 \%$ & $80.0 \%$ & $22.9 \%$ & $77.1 \%$ \\
\hline \multirow[t]{2}{*}{ Twice } & $\mathrm{T}$ & 81 & 227 & 71 & 237 & 70 & 238 & 68 & 240 & 73 & 235 \\
\hline & $\%$ & $26.3 \%$ & $73.7 \%$ & $23.1 \%$ & $76.9 \%$ & $22.7 \%$ & $77.3 \%$ & $22.1 \%$ & $77.9 \%$ & $23.7 \%$ & $76.3 \%$ \\
\hline \multirow[t]{2}{*}{ Three times } & $\mathrm{T}$ & 49 & 129 & 37 & 141 & 34 & 144 & 37 & 141 & 38 & 140 \\
\hline & $\%$ & $27.5 \%$ & $72.5 \%$ & $20.8 \%$ & $79.2 \%$ & $19.1 \%$ & $80.9 \%$ & $20.8 \%$ & $79.2 \%$ & $21.3 \%$ & $78.7 \%$ \\
\hline \multirow[t]{2}{*}{$\begin{array}{l}\text { Four times } \\
\text { and more }\end{array}$} & $\mathrm{T}$ & 18 & 100 & 13 & 105 & 10 & 108 & 10 & 108 & 10 & 108 \\
\hline & $\%$ & $15.3 \%$ & $84.7 \%$ & $11.0 \%$ & $89.0 \%$ & $8.5 \%$ & $91.5 \%$ & $8.5 \%$ & $91.5 \%$ & $8.5 \%$ & $91.5 \%$ \\
\hline \multirow[t]{2}{*}{ Total } & $\mathrm{T}$ & 298 & 935 & 242 & 991 & 238 & 995 & 241 & 992 & 265 & 968 \\
\hline & $\%$ & $24.2 \%$ & $75.8 \%$ & $19.6 \%$ & $80.4 \%$ & $19.3 \%$ & $80.7 \%$ & $19.5 \%$ & $80.5 \%$ & $21.5 \%$ & $78.5 \%$ \\
\hline \multicolumn{2}{|c|}{$\begin{array}{l}\text { correlation } \\
\text { coefficient PHI }\end{array}$} & \multicolumn{2}{|c|}{0.075} & \multicolumn{2}{|c|}{0.081} & \multicolumn{2}{|c|}{0.096} & \multicolumn{2}{|c|}{0.093} & \multicolumn{2}{|c|}{0.105} \\
\hline \multicolumn{2}{|c|}{ Probability value } & \multicolumn{2}{|c|}{0.072} & \multicolumn{2}{|c|}{$0.045^{*}$} & \multicolumn{2}{|c|}{$0.010^{*}$} & \multicolumn{2}{|c|}{$0.013^{*}$} & \multicolumn{2}{|c|}{$0.004 *$} \\
\hline
\end{tabular}

*With statistical significance at the level of significance $(\alpha=0.05)$. 


\section{Conclusions}

The study reached to the following conclusions:

- There is a statistically significant relationship between the common diseases among Saudi women and with the variable of area of residence, and was the highest proportion of common diseases among Saudi women who are residence in the eastern region.

- There is a statistically significant relationship between the common diseases among Saudi women and with the variable of age group. The highest proportion of common diseases among Saudi women is between the ages of $42-51$ years.

- There is a statistically significant relationship between the common diseases among Saudi women and with the variable of weight and was the highest proportion of common diseases among Saudi women who are their weigh $80 \mathrm{~kg}$ or above.

- There is a statistically significant relationship between the common diseases among Saudi women and with the level of education variable and was the highest proportion of common diseases among Saudi women who their education is medium.

- There is a statistically significant relationship between the common diseases among Saudi women and with the variable of nature of the profession, and was the highest proportion of common diseases among Saudi female teachers.

- There is a statistically significant relationship between the common diseases among Saudi women and with the variable of material situation, and was the highest proportion of common diseases among Saudi women divorcees.

- There is a statistically significant relationship between asthma among Saudi women and with the variable of practice sports activity. There is no statistically significant relationship between the common diseases among Saudi women and with the variable of practice sports activity.

- There is a statistically significant relationship between obesity among Saudi women and with the variable of number of children. There is no statistically significant relationship between the common diseases and with the variable of number of children.

- There is a statistically significant relationship between the common diseases among Saudi women and with the variable of justification practice of physical activity and was the highest proportion of common diseases among Saudi women who suffer from the satisfactory condition.

- There is a statistically significant relationship between the common diseases among Saudi women and with the variable rate of practice of physical activity per week and was the highest proportion of common diseases among Saudi women who practice physical activity twice a week.

\section{Recommendations}

In the following of the conclusions that reached by our study, it is to advise to follow the following recommendations

- The necessity of work to strengthen the role of culture in the promotion of physical activity by women, through health education by health centers in the Kingdom.

- Work on further studies regarding to the practicing of physical activities, sports exercise by Saudi women as preventive and curative strategy of common diseases.

- Focus on conducting joint studies between health, mental and physical education colleges to help Saudi women in facing the common diseases and facilitate their access to the necessary sports services according to their health condition.

\section{Acknowledgements}

This is a research project that was supported by a grant from: The Research Center for the Humanities, Deanship of Scientific Research at King Saud University.

\section{References}

Albaker, F., Meza, H., \& Alharamlh, A. (2013). Saudi women's attitudes towards sports activities and early intervention strategies to reduce the health consequences of them as a result of the low level for do these activities. Research presented to the scientific conference XIII of the science of sports psychology, the International Society of Sports Psychology ISSI, Beijing, China. 
Aljaffery, A. (2014). The students' attitudes of King Abdul Aziz University in Saudi Arabia towards physical activity. Najah University Journal for Research, 59-142.

Aljlad et al. (1992). Skin and venereal diseases (5th ed.). Damascus: Damascus University.

Bailey, R., Wellard, I., \& Dismore, H. (2004). Girls' participation in physical activities and sports: Benefits, patterns, influences and ways forward. Technical Report. World Health Organization.

C3 Collaborating for Health. (2011). Review: The Benefits of Physical Activity for Health and Well-Being, United Kingdom: C3 Collaborating for Health

Caetano, A., Tavares, M., \& Lopes, M., (2007). Urinary Incontinence and Physical Activity Practice. Rev Bras Med Esporte, 13(4): 245e-248e.

Clement, J. M. et. al. (2004). Obesity and Physical Activity in College Women: Implications for Clinical Practice. Journal of the American Academy of Nurse Practitioners, 16(7): 291-299. http://dx.doi.org/10.1111/j.1745-7599.2004.tb00452.x

Merza, H., Alharamlah, A., \& Albakr, F. (2013). Saudi women's attitudes towards sports activities and early intervention strategies to reduce the health consequences of them as a result of the low level for do these activities. Research presented to the scientific conference XIII of the science of sports psychology, the International Society of Sports Psychology ISSI, Beijing, China.

Midhet, F., Al Mohaimeed, A. R., \& Sharaf, F. (2010). Dietary Practices, Physical Activity and Health Education in Qassim Region of Saudi Arabia. International Journal of Health Sciences, 4(1), 3-10.

Reeder, R. (2011). Working Class African American Women and Heart Disease: How Communication and Community Impact Prevention Knowledge and Behaviors. Explorations: Social Sciences, Volume VI, $168-178$.

Sriskantharajah, J., \& Kai, J. (2007). Promoting Physical Activity among South Asian Women with Coronary Heart Disease and Diabetes: What Might Help? Family Practice, 24(1), 71-76. http://dx.doi.org/10.1093/fampra/cml066

Strohle, A. (2009). Physical Activity, Exercise, Depression and Anxiety Disorders. Journal Neural Transm, 116, 777-784. http://dx.doi.org/10.1007/s00702-008-0092-x

Wojtyła, A. et al. (2011). Physical Activity among Women at Reproductive Age and During Pregnancy (Youth Behavioural Polish Survey-YBPS and Pregnancy-related Assessment Monitoring Survey-PrAMS)-Epidemiological Population Studies in Poland During the Period 2010-2011. Annals of Agricultural and Environmental Medicine, 18(2), 365-374.

\section{Copyrights}

Copyright for this article is retained by the author(s), with first publication rights granted to the journal.

This is an open-access article distributed under the terms and conditions of the Creative Commons Attribution license (http://creativecommons.org/licenses/by/3.0/). 